\title{
Enhanced DPPH radical scavenging activity and DNA protection effect of litchi pericarp extract by Aspergillus awamori bioconversion
}

\author{
Sen Lin ${ }^{1,2}$, Bao Yang ${ }^{1}$, Feng Chen ${ }^{3}$, Guoxiang Jiang ${ }^{1,2}$, Qing Li ${ }^{1,2}, X_{\text {Uewu Duan }}{ }^{\text {and }}$ Yueming Jiang ${ }^{1 *}$
}

\begin{abstract}
Background: Litchi (Litchi chinensis Sonn.) pericarp is a major byproduct which contains a significant amount of polyphenol. This study was designed to biotransformation litchi pericarp extract (LPE) by Aspergillus awamori to produce more bioactive compounds with stronger antioxidant activities.

Results: The study exhibited that the 2,2-diphenyl-1-picrylhydrazyl radical scavenging activities significantly $(p<0.05)$ increased from $15.53 \%$ to $18.23 \%$ in the water-extracted fraction and from $25.41 \%$ to $36.82 \%$ in the ethyl acetate-extracted fraction. Application of DNA cleavage assay further demonstrated the enhanced protection effect of the fermented phenolics on DNA damage. It is also noted that the water-extracted fraction of the fermented LPE possessed a much stronger capacity than the ethyl acetate-extracted fraction to prevent from damage of supercoiled DNA. Interestingly, it was found that some new compounds such as catechin and quercetin appeared after of A. awamori fermentation of LPE, which could account for the enhanced antioxidant activity.

Conclusion: The DPPH radical scavenging activity and DNA protection effect of LPE were increased by Aspergillus awamori bioconversion while some compounds responsible for the enhanced antioxidant activity were identified. This study provided an effective way of utilizing fruit pericarp as a readily accessible source of the natural antioxidants in food industry and, thus, extended the application area such as fruit by-products.
\end{abstract}

Keywords: Litchi pericarp, Phenolics, Aspergillus awamori, DPPH radical scavenging activity, DNA protection, HPLC

\section{Background}

Phenolic compounds as secondary metabolites are widely present in fruits and vegetables. A positive relationship between consumption of food with abundant phenolics and low incidence of degenerative diseases, including cancer, heart disease, inflammation, arthritis, brain dysfunction and cataracts, has been confirmed [1]. Litchi (Litchi chinensis Sonn.) is a subtropical fruit with a brightly red pericarp which contains a significant amount of phenolics such as epicatechin, procyanidins, cyanidin3 -glucoside, and quercetin-3-rutinoside [2]. These phenolics exhibit good antioxidant ability [3], and anticancer and immunomodulatory activities [4].

\footnotetext{
* Correspondence: ymjiang@scbg.ac.cn

${ }^{1}$ Key Laboratory of Plant Resource Conservation and Sustainable Utilization, South China Botanical Garden, Chinese Academy of Sciences, Guangzhou 510650, People's Republic of China

Full list of author information is available at the end of the article
}

Currently, biotransformation of plant byproducts by microorganisms is one of an effective means to produce bioactive compounds. Many fruit byproducts, such as grape pomace, pineapple waste, citrus peel and banana peel, have been used to produce gluconic acid, carotenoids and citric acid by microorganism biotransformation [5-7]. Botella et al. [8] have used grape pomace as a solid substrate to produce xylanase and pectinase. Furthermore, grape pomace could induce the production of laccase for Trametes versicolor [9]. Some species of microorganisms belonging to the Aspergillus genus can produce tannase [10], naringinase [11], $\beta$-glucosidase [12], feruloyl esterase [13] and flavonol 2,4-dioxygenase [14], which make it possible to transform bioactive compounds. Hung et al. [15] have found that the antimutagenic activity of black bean can be increased after the treatment with Aspergillus. awamori. In the present work, A. awamori was chosen as a fermented microorganism to biotransformed litchi pericarp extract (LPE). The changes in the content and antioxidant activity of bioactive
() Chemistry Central

(c) 2012 Lin et al.; licensee Chemistry Central Ltd. This is an Open Access article distributed under the terms of the Creative Commons Attribution License (http://creativecommons.org/licenses/by/2.0), which permits unrestricted use, distribution, and reproduction in any medium, provided the original work is properly cited. 
compounds in litchi pericarp before and after biotransformation by $A$. awamori were investigated.

\section{Results}

\section{Contents of total phenolics and flavonoids}

As shown in Figure 1, the phenolic content of the water fraction of LPE decreased and then increased on the $15^{\text {th }}$ day in the fermentation period. On the contrary, the phenolic content of the ethyl acetate fraction of LPE decreased, then increased on the $6^{\text {th }}$ day and finally declined on the $15^{\text {th }}$ day. Similarly, a change in the flavonoid content of the water fraction was observed. In addition, when the fermentation with $A$. awamori on the Czapek-Dox medium without LPE was conducted, very small amounts of phenolics (i.e., 0.121, 0.093 and $0.046 \mathrm{mg} \mathrm{GAE} / \mathrm{ml}$ extract in the water fraction and $0.081,0.073$ and $0.066 \mathrm{mg} \mathrm{GAE} / \mathrm{ml}$ extract in the ethyl acetate fraction on the $3^{\text {rd }}, 6^{\text {th }}$ and $15^{\text {th }}$ day, respectively) were observed. However, no flavonoids can be detected in either the water fraction or the ethyl acetate fraction.

\section{Scavenging activity of DPPH radical}

As shown in Table 1, a great change in the DPPH radical scavenging activity occurred after fermentation with $A$.

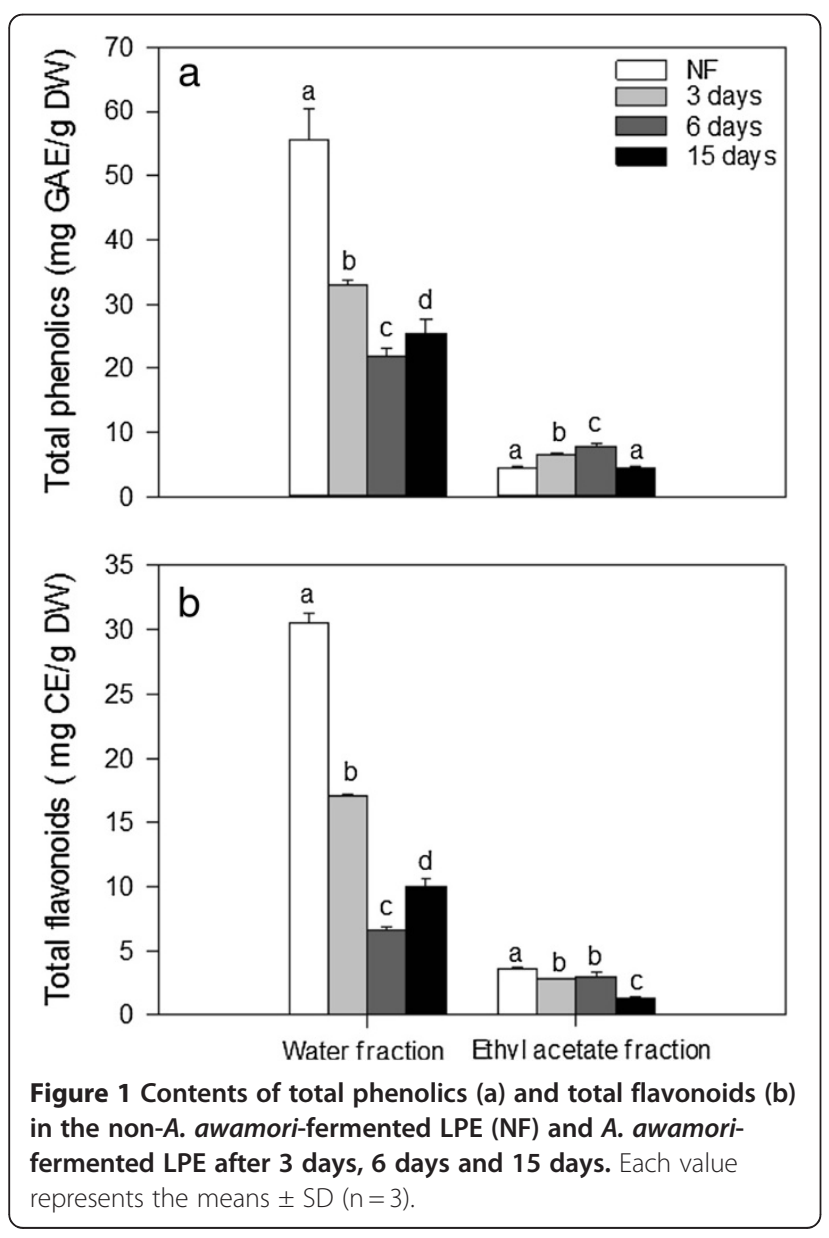

Table 1 DPPH radical scavenging activity of LPE

\begin{tabular}{lll}
\hline & \multicolumn{2}{c}{ DPPH radical scavenging activity (\%) } \\
\cline { 2 - 3 } & Water fraction & Ethyl acetate fraction \\
\hline $\begin{array}{l}3 \text { days-A. awamori-fermented } \\
\text { LPE }\end{array}$ & $18.23 \pm 1.06^{\mathrm{a}}$ & $19.5 \pm 1.12^{\mathrm{a}}$ \\
$\begin{array}{l}6 \text { days-A. awamori-fermented } \\
\text { LPE }\end{array}$ & $11.86 \pm 1.10^{\mathrm{b}}$ & $15.43 \pm 1.45^{\mathrm{b}}$ \\
$\begin{array}{l}15 \text { days-A. awamori- } \\
\text { fermented LPE }\end{array}$ & $12.53 \pm 1.16^{\mathrm{b}}$ & $36.82 \pm 2.19^{\mathrm{c}}$ \\
\end{tabular}

DPPH radical scavenging activities of LPE in the water-extracted fraction and ethyl acetate-extracted fraction in the absence of $A$. awamori were $15.53 \pm 1.36$ and $25.41 \pm 1.78$, respectively. Means followed by the same letter within a column were not significantly different at the $5 \%$ level.

awamori. Maximum value of DPPH radical scavenging activity of the water fraction of LPE was achieved after 3 days of fermentation, and then declined, which was associated with reduced phenolic content. The DPPH radical scavenging activity of the ethyl acetate fraction of LPE decreased within the first 6 days of fermentation, and then dramatically increased on the $15^{\text {th }}$ day. However, a poor DPPH radical scavenging activity was observed when fermented by $A$. awamori on the Czapek-Dox medium without LPE (data not shown). Moreover, no significant change in the DPPH scavenging activity of litchi pericarp extract in the absence of $A$. awamori was observed (data not shown) in the culture period. Thus, concentration and composition of phenolic compounds greatly affect the DPPH radical scavenging activity of LPE in this study. HPLC analysis showed that catechin (peak 6), a unidentified compound (peak 7) and quercetin (peak $6^{\prime}$ ) appearing on the $3^{\text {rd }}, 6^{\text {th }}$ and $15^{\text {th }}$ day during fermentation (Figure 2) may account for the increased $\mathrm{DPPH}$ radical scavenging activity of the A. awamorifermented LPE.

\section{DNA protection capacity}

Some human diseases such as cancer and neurodegenerative disease involve in imbalance between oxidant and antioxidant defense system. Oxidative DNA damage caused by reactive oxygen species including hydroxyl radical, superoxide anion, and hydrogen peroxide are responsible for these diseases [16]. In this study, DNA protection capacity was used to further investigate the effect of biotransformation on antioxidant capacity of A. awamori-fermented LPE. Plasmid DNA has three forms on agarose gel electrophoresis, namely supercoiled circular DNA, open circular form, and linear form. The $\cdot \mathrm{OH}$ radicals were able to cleave DNA strand (Lanes $C$ and D) resulting in the cleavage of supercoiled circular DNA to open circular and linear forms [17]. As shown in Figure 3, the water fraction of the A. awamorifermented LPE showed a better DNA protection ability (Lanes H, J and L), compared with non-A. awamorifermented LPE (Lane F). The DNA protection ability 

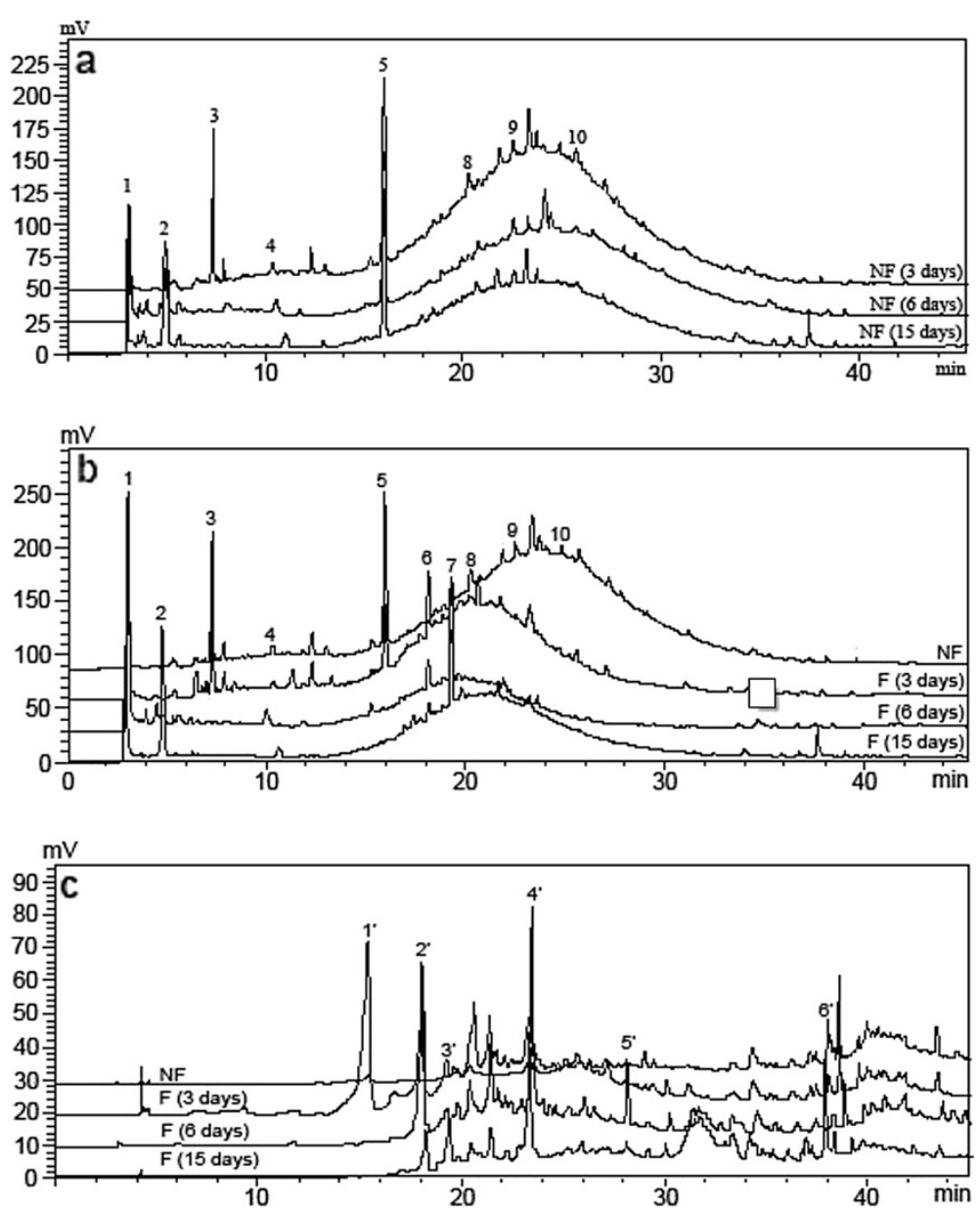

Figure 2 HPLC chromatograms of the A. awamori-fermented (F) or non-Aspergillus awamori-fermented (NF) LPE. Chromatogram (a), the water fraction of non-A. awamori-fermented LPE; Chromatogram (b), the water fraction of A. awamori-fermented LPE; and Chromatogram (c), the ethyl acetate fraction of the A. awamori-fermented LPE.

enhanced after 6 days of fermentation (Lane J) and then decreased after 15 days (Lane L). HPLC analysis showed that compound 7 appearing on the $6^{\text {th }}$ day during fermentation may account for the increased DNA protection of the A. awamori-fermented LPE. However, no DNA protection ability was observed in

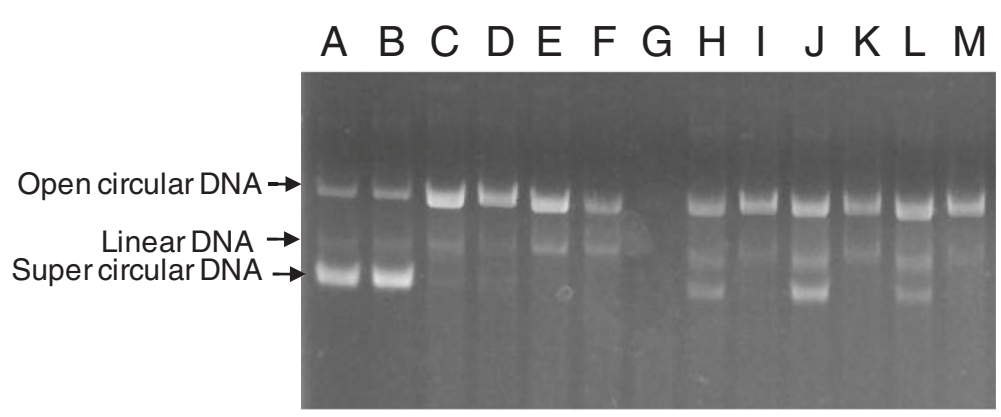

Figure 3 Electrophoretic patterns of plasmid DNA in the presence of LPE. A, water; B, water and ethanol; C, water and damage solution; $\mathbf{D}$, ethanol and damage solution; $\mathbf{E}, 100 \mu \mathrm{g} / \mathrm{ml}$ ascorbic acid and damage solution (negative control); $\mathbf{F}$, the water-extracted fraction of LPE with damage solution; $\mathbf{H}, \mathbf{J}$ and $\mathbf{L}$, the water-extracted fractions of the A. awamori-fermented LPE (after 3, 6 and 15 days of fermentation) with damage solution; $\mathbf{G}$, the ethyl acetate-extracted fraction of LPE with damage solution; and $\mathbf{I}, \mathbf{K}$ and $\mathbf{M}$, the ethyl acetate-extracted fraction of the $A$. awamori-fermented LPE (3, 6 and 15 days) with damage solution. 
the ethyl acetate fraction of both the A. awamori-fermented (Lanes I, $\mathrm{K}$ and $\mathrm{M}$ ) and non- $A$. awamori-fermented LPE (Lane G).

\section{HPLC analysis}

The HPLC chromatographic profiles of A. awamorifermented and non- $A$. awamori-fermented LPE are present in Figure 2. Based on the comparison of the retention time of standard compounds, procyanidin B1 (Peak 5), epicatechin (Peak 8) and epicatechin-3gallate (Peak 10) were identified in the non-A. awamorifermented LPE, while peaks 4, 6, 9 and 6' present in the $A$. awamori-fermented LPE were recognized as gallic acid, catechin, quercetin-3-glucoside and quercetin, respectively. However, some minor peaks were not identified due to lack of standard compounds in this present study. As shown in Figure 2a, a decrease of compound 3 along with an increase of compound 2 was observed in the non- $A$. awamori-fermented LPE in the fermentation period, possibly due to compound degradation or oxidization. Figure $2 \mathrm{~b}$ presents the HPLC profile of the water fraction LPE during fermentation by A. awamori. The contents of compounds 1 and 2 increased to the maximum value on the $6^{\text {th }}$ days and then decreased slightly. Meanwhile, compound 6 appeared on the $3^{\text {rd }}$ day and then decreased continuously while compound 7 appeared on the $6^{\text {th }}$ day and then increased continuously within 15 days. Figure 2c presents the HPLC profile of the ethyl acetate fraction of LPE during fermentation by $A$. awamori. A decrease of compound 1' along with an increase of compound 2' was observed on the $6^{\text {th }}$ day while the maximum contents of compounds 2', 4' and 5' were obtained on the $6^{\text {th }}$ day. Furthermore, the contents of compounds 3' and 6' reached the maximum values after 15 days of fermentation. In addition, in the culture extract of the Czapek-Dox medium of $A$. awamori without LPE, only a single peak was observed after 3 min of elution and no other peaks were found in further elution (date not shown), which drew a conclusion that the fungus could not synthesize those phenolic compounds such as compounds 6, 7, 1, 2' and 5' appearing in the A. awamori-fermented LPE. Regarding some unknown compounds, further investigation is needed to identify them in the fermented LPE by A. awamori.

\section{Discussion}

In this study, A. awamori was selected as the starter microorganism to biotransformed phenolic-rich LPE. After fermentation, the phenolic content of the water fraction dramatically decreased within the first 6 days and then increased on the $15^{\text {th }}$ days. Degradation and absorption of phenolics available used as a carbon source by $A$. awamori to maintain its growth may account for the decrease in the phenolic content within the first 6 days [18]. Natural degradation of phenolics in LPE without A. awamori was observed (data not shown). This is consistent with the finding of Huang et al. [19], who reported decrease of total phenolic content in black soybean koji during storage. Previous reports $[12,20,21]$ pointed out that some hydrolases (e.g. $\beta$-glucosidase, $\beta$-Xylosidase and $\alpha$-arabinofuranosidase) present in $A$. awamori were able to crack the linkages between phenolics and their glycosides to produce more hydrophobic compounds, which might account for the increased hydrophobic phenolic compounds in the present study. Similarly, a change in the content of flavonoid content of the water fraction of LPE was observed (Figure 1). Hund et al. [14] and Stoilova et al. [22] reported that some flavanoid-degrading enzymes such as quercetin 2,3-dioxygenase was present in A. niger or its variant. These enzymes can cleave $\mathrm{C} 2$ and $\mathrm{C} 3$ positions in $\mathrm{B}$ ring of quercetin to form 2-protocatechuoylphloroglucinol carboxylic acid [23]. The decrease in flavonoid content in the A. awamori-fermented LPE might be due to the action of these enzymes.

The effect of $A$. awamori on antioxidant properties of various plant material, such as black bean [24], wheat grain [25] and rice [26], were previously investigated. Among those studies, the increase in phenolic content after fermentation was supposed to be responsible for enhanced antioxidant activity. In this present study, DPPH scavenging activity of the LPE water fraction increased greatly while phenolic content decreased within the first 3 days. Moreover, a slight increase of phenolic content coupled with enhanced DPPH scavenging activity was observed in the LPE ethyl acetate fraction, which indicated that some compounds with higher DPPH scavenging capacity were produced after fermentation.

Plasmid DNA protection of LPE against Feton-reaction mediated breakage was used in this study. The water fraction of $A$. awamori-fermented LPE exhibited much higher DNA protection effect than the non-fermented fraction. However, no such effect was observed from both the $A$. awamori-fermented and non- A. awamorifermented ethyl acetate fractions. Aqueous extract rather than organic solvent extract of plant tissues such as black gram husk [27], Asplenium ceterach [28], and areca inflorescence [29] were reported to possess DNA protection activity. In this study, the results concerning DNA protection activity was not completely consistent with DPPH radical scavenging activity. Zhang [30] demonstrated that no significant correlation between DNA protection activity and DPPH radical scavenging activity was observed. Thus, application of DNA protection capacity to antioxidant activity evaluation was needed to be elucidated further.

To further understand the effect of the fermentation on individual phenolic compound, the phenolic profiles of the A. awamori-fermented and non-A. awamori- 
fermented LPE were determined by HPLC. The HPLC chromatogram revealed that the main phenolics present in non-A. awamori-fermented LPE were procyanidin B1 (Peak 5), epicatechin (Peak 8) and epicatechin-3-gallate (Peak 10), which were also reported by Zhang et al. [31] and Zhao et al. [32]. Great amount of compounds eluted as a hump at the retention time of $15-35$ min was in agreement with the report of Roux et al. [33], who demonstrated the hump as proanthocyanidins with different polymerization degree. After the fermentation of $A$. awamori, many peaks disappeared in the water fraction but appeared in the ethyl acetate fraction, which might be attributed to $\beta$-glucosidase produced by $A$. awamori [12] as the enzyme can hydrolyse glycosided flavonoids to more hydrophobic aglycones. This assumption was confirmed by the appearance of new compounds (Compounds 1', 2' and 4') after 3 days, and the presence of quercetin (Peak 6') and the absence of quercetin-3glucoside (Peak 9) after 6 days of fermentation. In this study, A. awamori could cleavage the $\mathrm{C} 4$ and $\mathrm{C} 8$ bond of procyanidin $\mathrm{B} 1$ and then form catechin and epicatechin which reduced the content of compound 5 but increased the contents of compound 6 (catechin) and compound 7 (unknown compound) on the $3^{\text {rd }}$ day of the fermentation (Figure 2b). Meanwhile, B-type procyanidin and catechin were reported to be further metabolized to more hydrophobic A-type procyanidin by some phenol oxidase $[34,35]$, which may account for the appearance of several compounds in the ethyl acetate fraction (Figure 2c).

$A$. awamori generally recognized as safe filamentous fungi [24] was widely present in traditional fermented foods (i.e. miso, natto and tempeh) in East Asia. In the present study, A. awamori was used to bioconvert the phenolics-rich LPE. To the best of our knowledge, the study was the first report on the increased antioxidant activity and DNA protection effect in relation to the conversion of phenolics of litchi pericarp by A. awamori. This work provided a better way of utilizing litchi pericarp as a readily accessible source of the natural antioxidants in food industry. The fermentation technology can further extend to the bioconversion of phenolic compounds in agriculture-derived by-products. Further investigation into the biochemical pathway of these phenolic compounds converted by A. awamori will be needed.

\section{Materials and methods Chemicals}

All chemicals used for preparing the Czapek-Dox medium were obtained from Guangzhou Reagent Co. (Guangzhou, China). Gallic acid, catechin, procyanidin B1, epicatechin3-gallate, quercetin, and quercetin-3-glucoside were purchased from Sigma Chemical Co (St. Louis, MO, USA). Methanol used for HPLC analysis was obtained from CNW Technologies Gmbh (Dusseldorf, Germany).

\section{Litchi pericarp and starter microorganism}

Fresh fruit of litchi (Litchi chinensis Sonn.) cv. Huaizhi were harvested from a commercial orchard in Guangzhou, China. The fruit were cleaned carefully with distilled water, and then peeled manually. The pericarp was collected, then dried out door, and finally ground into powder by a grinder (DFT-50, Lingda Mechanics Co., Zhejiang, China).

The microorganism Aspergillus awamori GIM 3.4 was obtained from Guangdong Culture Collection Center, Guangzhou, China. The fungus was cultured for 3 days on potato dextrose agar (Guangdong Huankai Microbial Science \& Technology Co., Ltd, Guangzhou, China) at $30^{\circ} \mathrm{C}$, and then the spores were collected by washing the agar surface with sterile distilled water containing $0.1 \%$ Tween 80 . The spore suspension was finally adjusted to a concentration of ca. $10^{6} / \mathrm{ml}$ with sterile distilled water, which was served as inoculum for the fermentation of litchi pericarp.

\section{Biotransformation of litchi pericarp extract}

Litchi pericarp powder (100 g) was extracted twice with $500 \mathrm{ml}$ of $60 \%(\mathrm{v} / \mathrm{v})$ ethanol coupled with ultrasonic treatment $\left(40 \mathrm{~min}\right.$ at $210 \mathrm{w}$ and $\left.30^{\circ} \mathrm{C}\right)$. After filtration through Whatman No. 1 filter paper, litchi pericarp extract (LPE) was concentrated at $50^{\circ} \mathrm{C}$ using a rotary evaporator under vacuum to remove ethanol, and then adjusted to $500 \mathrm{ml}$ with distilled water. Fresh spore suspension $(1 \mathrm{ml})$ of $A$. awamori was incubated with the sterilized $\left(121^{\circ} \mathrm{C}, 30 \mathrm{~min}\right)$ Czapek-Dox medium $(100 \mathrm{ml})$ containing $\mathrm{NaNO}_{3}(0.3 \mathrm{~g}), \mathrm{K}_{2} \mathrm{HPO}_{4}(0.1 \mathrm{~g})$, $\mathrm{KCl}(0.05 \mathrm{~g}), \mathrm{MgSO}_{4} .7 \mathrm{H}_{2} \mathrm{O}(0.05 \mathrm{~g}), \mathrm{FeSO}_{4}(0.001 \mathrm{~g})$, sucrose $(3 \mathrm{~g})$, LPE $(15 \mathrm{ml})$ and distilled water $(85 \mathrm{ml})$. The inoculated flasks were then cultured at $30^{\circ} \mathrm{C}$ with shaking at $130 \mathrm{rpm}$. In addition, incubation of fresh spore suspension $(1 \mathrm{ml})$ with the Czapek-Dox medium $(100 \mathrm{ml})$ without the LPE was also conducted under the same condition. After incubation for 3, 6 or 15 days, the fermented product $(100 \mathrm{ml})$ was filtered through the Whatman No. 1 filter paper and then extracted twice with ethyl acetate $(50 \mathrm{ml})$. The ethyl acetate fraction was concentrated under vacuum and then re-dissolved with absolute ethanol $(50 \mathrm{ml})$, while the hydrophilic fraction was vacuum concentrated to $50 \mathrm{ml}$. These fractions were collected and then stored at $4^{\circ} \mathrm{C}$ for further analyses.

\section{Measurements of total phenolic and flavonoid contents}

The measurement of total phenolic content was conducted by the method as described by Quettier-Deleu et al. [36], with some modifications. An aliquot $(0.1 \mathrm{ml})$ of these samples was mixed with $5 \mathrm{ml}$ of distilled water and $0.5 \mathrm{ml}$ of Folin-Ciocalteu phenol reagent. After incubation for $8 \mathrm{~min}, 20 \% \mathrm{Na}_{2} \mathrm{CO}_{3}(1.5 \mathrm{ml})$ were added 
and heated in boiling water for $1 \mathrm{~min}$. Absorbance was recorded at $760 \mathrm{~nm}$ at $25^{\circ} \mathrm{C}$ in dark. Gallic acid was used to make a calibration curve. Phenolic content was expressed as mg gallic acid equivalent per gram on a dry weigh basis (mg GAE/g DW). All testes were conducted in triplicate.

The total flavonoid content was determined according to the method of Jia et al. [37], with some modifications. Sample or $(+)$-catechin standard $(1 \mathrm{ml})$ was mixed with $4 \mathrm{ml}$ of distilled water and $0.5 \mathrm{ml}$ of $5 \%$ sodium nitrite. After incubation for $6 \mathrm{~min}, 0.5 \mathrm{ml}$ of $10 \%$ aluminum nitrate was added, and then allowed to stand for another 5 min before $4 \mathrm{ml}$ of $1 \mathrm{M} \mathrm{NaOH}$ were added. The absorbance was measured immediately against the methanol blank at $510 \mathrm{~nm}$ using a spectrophotometer (Uico Shangshai Instrument Co. Ltd., Shanghai, China) in comparison with the standard $(+)$-catechin. Total flavonoid content was expressed as $\mathrm{mg}$ catechin equivalent per gram on a dry weigh basis (mg CE/g DW). All testes were conducted in triplicate.

\section{Assay of DPPH radical scavenging activity}

The method described by Sánchez-Moreno et al. [38] was used to assess the scavenging activity of DPPH free radicals. Briefly, samples were diluted to $100 \mu \mathrm{g}$ of total phenolics per $\mathrm{ml}$, and then an aliquot $(0.1 \mathrm{ml})$ of the diluted sample was mixed with $2.9 \mathrm{ml}$ of $0.1 \mathrm{mM}$ DPPH solution in methanol. The absorbance was measured at $517 \mathrm{~nm}$ after $30 \mathrm{~min}$ of incubation at $25^{\circ} \mathrm{C}$. The control was carried out with water or ethanol instead of the tested sample, and methanol instead of DPPH was used as blank. The antiradical activity (AA) of the tested sample was calculated using the following formula:

$$
\begin{aligned}
\text { AA }(\%)= & \left(1-\frac{\text { absorbance of sample }- \text { absorbance of blank }}{\text { absorbance of control }}\right) \\
& \times 100
\end{aligned}
$$

\section{Protection against DNA breakage}

The assay was conducted to determine the protective ability of the A. awamori-fermented and non-A. awamori-fermented LPE against supercoiled DNA by the method of Kang et al. [17], with some modifications. Escherichia coli DH5a cells were transformed with pUC19 plasmid DNA and then grown overnight in the LB medium containing ampicillin $(50 \mu \mathrm{g} / \mathrm{ml})$ at $37^{\circ} \mathrm{C}$. Plasmid DNA was purified using the UNIQ-10 Plasmid Kit (Wuhan Sikete Science \& Technology Development Co., Ltd., China). The damage solution $(1 \mathrm{mM} \cdot \mathrm{OH})$ was prepared by adding $3.1 \mu \mathrm{l}$ of $30 \% \mathrm{H}_{2} \mathrm{O}_{2}$ into $100 \mathrm{ml}$ of $1 \mathrm{mM} \mathrm{FeSO}_{4}$. The reaction solution consisted of $5 \mu \mathrm{l}$ of plasmid DNA, $5 \mu \mathrm{L}$ of damage solution, and $5 \mu \mathrm{l}$ of the tested sample. Three microlitres of loading buffer [30 mM EDTA, 36\% (v/v) glycerol, 0.05\% $(\mathrm{w} / \mathrm{v})$ xylene cyanol FF and $0.05 \%(\mathrm{w} / \mathrm{v})$ bromophenol blue] were added after 1 hour of incubation in dark, and the reaction products were then electrophoresized in $1 \%$ of agarose gel for $40 \mathrm{~min}$ under $120 \mathrm{~V}$ condition. Agarose gel was stained with $0.05 \%(\mathrm{w} / \mathrm{v})$ ethidium bromide and then analyzed with image analyzer (Image station 2000R, Kodak, New York, USA).

\section{HPLC analysis of phenolic compounds}

All samples were filtered through a membrane with $0.45-\mu \mathrm{m}$ pore size prior to injection. Separation, analysis and quantification of phenolic compounds were performed using a Shimadzu LC-20 AT (Shimadzu Corporation, Japan) separation module coupled with a Vydac C18 column (218 TP, $250 \times 4.6 \mathrm{~mm}, 5 \mu \mathrm{m}$ of particle size, Sigma-Aldrich, St. Louis, MO, USA) and a SPD-10A UV-VIS detector by the method of Yang and Zai [39]. Solvent A (0.1\% trifluoroacetic acid) and B (methanol) were used as the mobile phases, with a flow rate of $1 \mathrm{ml} / \mathrm{min}$. The gradient elution program was as follows: 0-5 min, 10\% B; 5-35 min, 10-100\% B; 35-40 min, $100 \% \mathrm{~B}$; and $40-45 \mathrm{~min}, 10 \% \mathrm{~B}$. The temperature of the column was maintained at $25^{\circ} \mathrm{C}$. The injection volume was $20 \mu \mathrm{l}$. The chromatogram was recorded at $280 \mathrm{~nm}$. Identification of phenolic compounds was estimated on the basis of retention time.

\section{Statistical analysis}

Data were expressed as means \pm standard deviations (SD) and then analyzed by OriginPro 8 (OriginLab Corporation, Massachusetts,USA). The graphs were done using Sigmaplot (Systat Software Inc., San Joes. CA). Oneway analysis of variance (ANOVA) with Turkey's post-hoc test was applied for multiple comparisons. Differences between means at the $5 \%$ level were considered significant.

\section{Conclusions}

The results demonstrated that increased antioxidant activity was produced after fermentation of LPE with A. awamori. The water-extracted fraction of the fermented LPE possessed more DNA protection capacity. HPLC analysis showed that some new compounds such as catechin and quercetin appeared after of $A$. awamori fermentation of LPE, which could account for the increased antioxidant activity and enhanced DNA protection capacity.

\section{Competing interests}

The authors declare that they have no competing interests.

\section{Authors' contributions}

SL made a significant contribution to acquisition of data, analysis and manuscript preparation. BY has made a substantial contribution to experimental design and data analysis. FC participated in study design and manuscript revision. GJ participated in partial experiments. QL participated in partial experiments. XD participated in experimental design and data analysis. YJ made a significant contribution to experimental design, data analysis, and manuscript revision. All authors read and approved the final manuscript. 


\section{Acknowledgements}

Financial support from the Special Fund for Agricultural Research in the Public Interest (grant no. 200903043), the National Natural Science Foundation of China (grant No. 31071638), Guangdong Province Science and Technology Project (grant No. 2009B040600004), Knowledge Innovation Program of Chinese Academy of Sciences (grant No. KSCX2-EW-J-28), Youth Innovation Promotion Association of Chinese Academy of Sciences, and International Foundation for Science (grant No. F/4451-2).

\section{Author details}

'Key Laboratory of Plant Resource Conservation and Sustainable Utilization, South China Botanical Garden, Chinese Academy of Sciences, Guangzhou 510650, People's Republic of China. ${ }^{2}$ Graduate School of Chinese Academy of Sciences, Beijing 100039, People's Republic of China. ${ }^{3}$ Department of Food, Nutrition and Packaging Sciences, Clemson University, Clemson, SC 29634, USA

Received: 10 August 2012 Accepted: 25 September 2012 Published: 27 September 2012

\section{References}

1. Kris-Etherton PM, Hecker KD, Bonanome A, Coval SM, Binkoski AE, Hilpert KF, Griel AE, Etherton TD: Bioactive compounds in foods: their role in the prevention of cardioascular disease and cancer. Am J Med 2002, 113:71s-88s.

2. Sarni-Manchado P, Roux EL, Guerneve CL, Lozano Y, Cheynier V: Phenolic composition of litchi fruit pericarp. J Agric Food Chem 2000, 48:5995-6002.

3. Duan XW, Jiang $Y M$, Su XG, Zhang ZQ, Shi J: Antioxidant properties of anthocyanins extracted from litchi (Litchi chinenesis Sonn.) fruit pericarp tissues in relation to their role in the pericarp browning. Food Chem 2007, 101:1365-1371.

4. Zhao M, Yang B, Wang J, Liu Y, Yu L, Jiang Y: Immunomodulatory and anticancer activities of flavonoids extracted from litchi (Litchi chinensis Sonn.) pericarp. Int Immunopharmacol 2007, 7:162-166.

5. Imandi SB, Bandaru WR, Somalanka SR, Bandaru SR, Garapati HR: Application of statistical experimental designs for the optimization of medium constituents for the production of citric acid from pineapple waste. Bioresource Technol 2008, 99:4445-4450

6. Karthikeyan A, Sivakumar N: Citric acid production by koji fermentation using banana peel as a novel substrate. Bioresource Technol 2010, 101:5552-5556.

7. Buzzini P, Gobbetti M, Rossi J, Ribaldi M: Utilization of grape must and concentrated rectified grape must to produce gluconic acid by Aspergillus niger, In batch fermentations. Biotechnol Lett 1993, 15:151-156.

8. Botella C, Ory I, Webb C, Cantero D, Blandino A: Hydrolytic enzyme production by Aspergillus awamori on grape pomace. Biochem Eng J 2005, 26:100-106.

9. Lorenzo M, Moldes D, Couto SR, Sanromán A: Improve laccase production by employing different lignocellusic wastes in submerged cultures. Bioresource Technol 2002, 82:109-113.

10. Chhokar V, Sangwan M, Beniwal V, Nehra K, Nehra KS: Effect of additives on the activity of tannase from Aspergillus awamori MTCC9299. Appl Biochem Biotech 2010, 160:2256-2264.

11. VinothKumar V, ReyathiBabu PKS: Optimization of fermentation parameters for enhanced production of naringinase by soil isolate Aspergillus niger VB07. Food Sci Biotechnol 2010, 19:827-829.

12. Gottschalk LMF, Oliveira RA, Bon EPD: Cellulases, xylanases, $\beta$-glucosidase and ferulic acid esterase produced by Trichoderma and Aspergillus act synergistically in the hydrolysis of sugarcane bagasse. Biochem Eng J 2010, 51:72-78.

13. Fazary AE, Hamad HA, Lee JC, Koskei T, Lee C-K, Ju Y-H: Expression of feruloyl esterase from Aspergillus awamori in Escherichia coli: Characterization and crystal studies of the recombinant enzyme. Int J Biol Macromol 2010, 46:440-444.

14. Hund H-K, Breuer J, Lingens F, Hüttermann J, Kappl R, Fetzner S: Flavonol 2,4-dioxygenase from spergillus niger DSM 821, a type 2 Cu containing glycoprotein. Eur J Biochem 1999, 263:871-878.

15. Hung Y, Wang Y, Chou C: Antimutagenic activity of Aspergillus awamorifermented black soybean response to simulated digestive juice treatments and its antimutagenic mechanisms. LWT - Food Sci Technol 2009, 42:56-62.
16. Barnham KJ, Masters CL, Bush Al: Neurodegenerative diseases and oxidative stress. Nat Rev Drug Discov 2004, 3:205-214.

17. Kang HS, Kim KR, Jun EM, Park SH, Lee TS, Suh J-W, Kim J-P: Cyathuscavins $A, B$, and $C$, new free radical scavengers with DNA protection activity from the Basidiomycete Cyathus stercoreus. Bioorg Med Chem Lett 2008, $18: 4047-4050$

18. Stoilova I, Krastanov A, Stanchev V, Daniel D, Gerginova M, Alexieva Z: Biodegradation of high amounts of phenol, catechol, 2,4-dichlorophenol and 2,6-dimethoxyphenol by Aspergillus awamori cells. Enzyme Microb Tech 2006, 39:1036-1041.

19. Huang RY, Wang YJ, Sheen LY, Chou CC: Storage temperature and packaging condition affect the total phenolic content and antioxidant activity of black soybeans and koji. Int J Food Sci Technol 2010, 45:437-443.

20. Wood TM, McCrae SI: Arabinoxylan-degrading enzyme system of the fungus Aspergillus awamori: Purification and properties of an a-Larabinofuranosidase. Appl Microbiol Biot 1996, 45:538-545.

21. Smith DC, Wood TM: Xylanase Production by Aspergillus awamori Development of a medium and optimization of the fermentation parameters for the production of extracellular xylanase and $\beta$-Xylosidase while maintaining low protease production. Biotechnol Bioeng 1991, 38:883-890.

22. Stoilova I, Krastanov A, Yanakieva I, Kratchanova M, Yemendjiev H: Biodegradation of mixed phenolic compounds by Aspergillus awamori NRRL 3112. Int Biodeter Biodegr 2007, 60:342-346.

23. Schroder G, Wehinger E, Lukacin R, Frank W, Seefelder W, Schwab W, Schroder J: Flavonoid methylation: a novel 4'-O-methyltransferase from Catharanthus roseus, and evidence that partially methylated flavanones are substrates of four different flavonoid dioxygenases. Phytochem Lett 2004, 65:1085-1094.

24. Lee IH, Hung YH, Chou CC: Solid-state fermentation with fungi to enhance the antioxidative activity, total phenolic and anthocyanin contents of black bean. Int J Food Microbiol 2008, 121:150-156.

25. Bhanja T, Kumari A, Banerjee R: Enrichment of phenolics and free radical scavenging property of wheat koji prepared with two filamentous fungi. Bioresource Technol 2009, 100:2861-2866.

26. Miyake Y, Mochizuki M, Ito C, Itoigawa M, Osawa T: Antioxidative pyranonigrins in rice mold starters and their suppressive effect on the expression of blood adhesion molecules. Biosci Biotech Bioch 2008 72:1580-1585

27. Girish TK, Vasudevaraju P, Prasada Rao UJS: Protection of DNA and erythrocytes from free radical induced oxidative damage by black gram (Vigna mungo L.) husk extract. Food Chem Toxicol 2012, 50:1690-1696.

28. Berk S, Tepe B, Arslan S, Sarikurkcu C: Screening of the antioxidant, antimicrobial and DNA damage protection potentials of the aqueous extract of Asplenium ceterach DC. Afr J Biotechnol 2011, 10:8902-8908.

29. Chen WJ, Zhang CM, Huang YL, Cheng FF, Zhao SL, Shen Y, Liu JK: DNA damage protection and 5-lipoxygenase inhibiting activity of areca (Areca catechu L.) inflorescence extracts. Afr J Biotechnol 2011, 10:11696-11702.

30. Zhang $L$, Yang $X$, Zhang $Y$, Wang $L$, Zhang R: In vitro antioxidant properties of different parts of pomegranate flowers. Food Bioprod Process 2011, 89:234-240.

31. Zhang D, Quantick PC, Grigor JM: Changes in phenolic compounds in litchi (Litchi chinensis Sonn.) fruit during postharvest storage. Postharvest Biol Technol 2000, 19:165-172.

32. Zhao M, Yang B, Wang J, Li B, Jiang Y: Identification of the major flavonoids from pericarp tissues of lychee fruit in relation to their antioxidant activities. Food Chem 2006, 98:539-544.

33. Roux EL, Doco T, Sarni-Manchado P, Lozano Y, Cheynier V: A-type proanthocyanidins from pericarp of Litchi chinensis. Phytochemistry 1998, 48:1251-1258

34. Osman AM, Wong KKY: Laccase (EC 1.10.3.2) catalyses the conversion of procyanidin B-2 (epicatechin dimer) to type A-2. Tetrahedron Lett 2007, 48:1163-1167.

35. Osman AM, Wong KKY, Fernyhough A: The laccase/ABTS system oxidizes (+)-catechin to oligomeric products. Enzyme Microb Tech 2007, 40:1272-1279.

36. Quettier-Deleu C, Gressier B, Vasseur J, Dine T, Brunet C, Luyckx M, Cazin M, Cazin JC, Bailleul F, Trotin F: Phenolic compounds and antioxidant activities of buckwheat (Fagopyrum esculentum Moench) hulls and flour. J Ethnopharmacol 2000, 72:35-42. 
37. Jia Z, Tang M, Wu J: The determination of flavonoid contents in mulberry and their scavenging effects on superoxide radicals. Food Chem 1999, 64:555-559.

38. Sánchez-Moreno C, Larrauri JA, Saura-Calixto F: A procedure to measure the antiradical efficiency of polyphenols. J Sci Food Agr 1998, 76:270-276.

39. Yang Z, Zhai W: Identification and antioxidant activity of anthocyanins extracted from the seed and cob of purple corn (Zea mays L.). Inno Food Sci Emerg 2010, 11:169-176.

Cite this article as: Lin et al:: Enhanced DPPH radical scavenging activity and DNA protection effect of litchi pericarp extract by Aspergillus awamori bioconversion. Chemistry Central Journal 2012 6:108.

\section{Publish with ChemistryCentral and every scientist can read your work free of charge \\ "Open access provides opportunities to our colleagues in other parts of the globe, by allowing anyone to view the content free of charge." \\ W. Jeffery Hurst, The Hershey Company. \\ - available free of charge to the entire scientific community \\ - peer reviewed and published immediately upon acceptance \\ - cited in PubMed and archived on PubMed Central \\ - yours - you keep the copyright \\ Submit your manuscript here: \\ http://www.chemistrycentral.com/manuscript/<smiles>c1ccccc1</smiles> 